\title{
Typology and spatial cognition in English, French and Greek: evidence from eye-tracking
}

Efstathia Soroli

Structures Formelles du Langage Lab, CNRS \& University of Paris8, France

https://doi.org/10.36505/ExLing-2011/04/0031/000200

\begin{abstract}
Languages encode space in strikingly different ways (Talmy, 2000): Satelliteframed languages (e.g., English) lexicalize Manner in verb roots and express Path in satellites, whereas Verb-framed languages (e.g., French) lexicalize Path in verb roots, leaving Manner implicit or peripheral; other languages present parallel systems in which both Verb- and Satellite-framed structures are available (e.g., Greek). The present study investigates how speakers of three typologically different languages, English, French and Greek, performed a production task and allocated their visual attention while exploring and describing visual scenes involving motion events. The findings show that participants' verbalizations and eye-movement fixations differed substantially as a function of language-specific factors, arguing that typological constraints have a clear impact not only on linguistic but also on non-linguistic behaviours.
\end{abstract}

Key words: spatial cognition, language typology, production, eye-tracking method.

\section{Introduction}

Languages map semantic elements in very different ways when expressing motion. Talmy (2000) classifies languages into: satelliteframed (e.g., English) and verb-framed (e.g., French); the former are languages that lexicalize the Manner of motion in the verb and use satellites (e.g., particles) to express Path information within one compact structure (see example 1); the latter are languages that lexicalize Path in the verb stem, leaving Manner information implicit or placing it at the periphery of the sentence (e.g., gerunds/adverbials), (see example 2).

(1) A man is running into a house.

$$
\text { MANNER PATH (S-framed pattern) }
$$

(2) Il entre dans une maison en courant.
PATH
MANNER

Lit. 'He is entering in[to] the house by running.' (V-framed pattern)

Another type of languages can equally manifest structures of both types. Greek displays such a mixed system, as illustrated in (3-4). However, for some authors, Greek is clearly a verb-framed language (Papafragou et al., 2006; Selimis, 2007), in which the $V$-pattern is dominant.

\section{(3) Efyge trehontas (pros ta pano)}

ExLing 2011: Proceedings of 4th Tutorial and Research Workshop on Experimental Linguistics, 25-27 May, Paris, France 


\section{Path Manner Path}

Left running (to-upwards)

'He left running upwards' (V-framed pattern)

(4) Etrekse mesa sto spiti

MANNER PATH PATH

Ran into to-the house'

'He ran into the house'

(S-framed pattern)

An additional issue relevant to the typological classification of Greek is prefixation. Greek exhibits a set of preverbs of motion verbs (e.g., $\alpha v \varepsilon \beta \alpha \dot{\zeta} \omega \omega$, 'to up-put'; $\varepsilon \xi \xi \dot{\varepsilon} \rho \chi 0 \mu \alpha 1$, 'to out-come'; $\kappa \alpha \tau \varepsilon \beta \alpha i v \omega$ 'to down-walk/go'; $\xi \varepsilon \gamma \lambda ı \tau \tau \omega \dot{~ ' t o ~ o u t-s l i d e ') ~ w h i c h ~ f u n c t i o n ~ a s ~ s a t e l l i t e s ~ f o r ~ M o t i o n, ~ P a t h ~ a n d / o r ~}$ Manner verb roots. However, little is known about this phenomenon, which may raise important arguments regarding the real typological status of Greek. In the present study I examine preverbs of this type and the option of an additional $S$-framed sub-pattern that may exist as a result of verbal prefixes that share properties of satellites, as illustrated in (5).

(5) Anevike trehontas

$\begin{array}{ll}\text { Ana[prefix]-veno[Manner V-root] } & \text { treho[Manner V-gerund] } \\ \text { PATH MANNER/MOTION } & \text { MANNER } \\ \text { up-walked/went } & \text { running } \\ \text { 'He ascended running' } & \text { (S-framed prefixed pattern) }\end{array}$

Such striking cross-linguistic differences, apart from their typological interest, are significant for the study of the relationship between language and cognition, and contribute to the debate opposing universalist approaches-according to which spatial cognition is based on universal perceptual and cognitive processes that are independent from languagespecific properties-and relativity approaches-according to which language-specific factors affect how speakers construct spatial representations. In the context of this debate and while most studies showing language effects have been based on language use (Hickmann, et al. 2009; Slobin, 2006), the present study analyses verbal and non-verbal responses of speakers of typologically different languages (cf. Soroli \& Hickmann, 2010a) in order to determine the extent to which language properties influence different measures of cognition.

\section{Method}

The present study investigated how 42 native speakers of English, French and Greek (14 per language) performed a verbal task and allocated their visual attention while exploring and describing visual scenes (clips) 
involving events of voluntary motion. The analysis of the verbal measures examined two aspects of the responses: the types of information selected for expression (focus) and the means whereby this information was expressed (locus). In Greek (see Soroli \& Hickmann 2010b; Hickmann et al., submitted), the data were coded twice (Verb-vs. Satellite-coding). V-coding did not differentiate prefixed and plain verb forms, while $S$-coding decomposed prefixed verb forms into a verbal root and a satellite-like verbal prefix. As a result, verbal prefixes were treated as part of the verb in $V$ coding, but not in $S$-coding. The analysis of eye-movements examined the number, length and timeline of the fixations in specific areas of interest (Path vs. Path \pm Manner) in the clips.

\section{Results and discussion}

Subjects' verbalizations differed substantially as a function of languagespecific factors. English speakers used compact structures that expressed both Manner and Path information and in which they systematically encoded Manner in verbs and Path in other devices. In contrast, French speakers mostly focused on Path information that was expressed in the verb, and either provided less information about Manner in the periphery of the sentence or did not use any other devices in the verbal network to express this information. As for Greek, it seems to present a third pattern, since some utterances seem to be $V$-framed, others are $S$-framed, and a third group seem to belong to an $S$-framed sub-system comprising Path prefixes. These patterns directly follow from language-specific factors that typologically differentiate English, French and Greek as Satellite-, Verb- and Parallelframed languages respectively.

Turning now to eye-movements, although all speakers allocated more attention to Path overall, their focus also varied across language groups in all measures. More specifically, French speakers focused their gaze mostly on Path areas and this from stimulus onset until the end of the processing timeline. In contrast, the gazes of English and Greek speakers showed no preference for Path or Path \pm Manner areas of interest, with the exception of brief Path preferences at the onset of the stimuli for English speakers.

\section{Conclusion}

Overall the verbal and non-verbal findings point to differences in behavioural patterns as a function of typological language properties. In conclusion, we argue that typological constraints have a clear impact on linguistic behaviour, but also on non-linguistic behaviour. Such results contribute to current debates concerning the language-thought interface. In particular, linguistic analyses based on controlled methodologies, such as the one that was used in the present study, can yield comparable databases 
across a number of languages, thereby making it possible to put forth finegrained and realistic hypotheses concerning the cognitive implications of typological properties.

\section{Acknowledgements}

I wish to thank Maya Hickmann for kindly providing her stimuli for this study and precious advice. Eleni Valma, Stathis Selimis, Zaphira Rohde, Christina Papadimitraki and Annemarie Verkerk, for much discussion and feedback on Greek. I am especially grateful to Lina Soroli, Sofien Guedanna, Maria Papageorgiou, Yiannis Vlassopoulos and Jean-René Borelly for help in experiment preparation and much inspiring discussion.

\section{References}

Hickmann, M., Tarrane, P., Bonnet, Ph. 2009. Motion in first language acquisition: Manner and Path in French and in English. Journal of Child Language, Vol 36, Issue 04, 705-741.

Hickmann, M., Hendriks, H., Soroli, E., Iakovleva, T., Ji, Y. submitted. Space and language typology : encoding motion across languages.

Papafragou, A., Massey, C., Gleitman, L. 2006. When English proposes what Greek presupposes: The linguistic encoding of motion events. Cognition, 98, B75-B87.

Selimis, E. 2007. Г

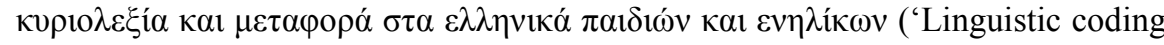
of the concept of motion: Literal and metaphorical expressions in adult and child Greek'). Unpublished Doctoral dissertation, University of Athens.

Slobin, D.I. 2006. What makes manner of motion salient? Explorations in linguistic typology, discourse, and cognition. In M. Hickmann, S. Robert (Eds.), Space across languages: linguistic systems and cognitive categories, 59-81. Amsterdam: John Benjamins.

Soroli, E., Hickmann, M. 2010a. Language and spatial representations in French and in English : evidence from eye-movements. In G. Marotta, A. Lenci, L. Meini\& F. Rovai (Eds.), Space in Language, 581-597. Pisa : Editrice Testi Scientifici.

Soroli, E., Hickmann, M. 2010b. Crosslinguistic spatial cognition: exploring visuospatial thinking and speaking. Presented at the Summer Institute in Cognitive Sciences 2010: The Origins of Language. Montreal, Canada, June 21-30, 2010

Talmy, L. 2000. Toward a cognitive semantics. Volume 1: Concept structuring systems. Volume 2: Typology and process in concept structuring. Cambridge, MA: MIT Press. 